\title{
O suíço Johann Jakob Von Tschudi (1818-1889) e suas leituras da América do Sul
}

\author{
The swiss Johann Jakob Von Tschudi (1818-1889) \\ and his readings of South America
}

Martin N. Dreher*

\begin{abstract}
Resumo: Natural de Glarus, na Suíça, Johann Jakob Von Tschudi esteve pela primeira vez na América do Sul entre 1838 a 1843, quando permaneceu no Peru. De 1857 a 1859 esteve pela primeira vez no Brasil, país ao qual retornaria em 1860, na qualidade de embaixador da Confederação Helvética. Aqui permaneceu até 1868. Destas permanências resultaram diversas obras, entre as quais merecem destaque os 5 volumes de suas Reisen durch Südamerika (Viagens pela América do Sul), obra publicada em Leipzig pela Editora Brockhaus entre os anos de 1866 e 1869 e fartamente ilustrada com bicos de pena. Incumbido pela Confederação Helvética de verificar a situação de emigrados dos cantões suíços, após a crise provocada pelo levante da Fazenda Ibicaba, da qual Thomas Davatz nos deixou importante memória, Tschudi não só nos legou a memória desta imigração, mas também a de outros grupos étnicos europeus, merecendo destaque seus choques com populações indígenas, e suas leituras das populações africanas. Além de descrições da vida urbana e rural na América do Sul, a obra é importante fonte para as leituras de europeus sobre o continente. Nossa proposta é apresentar a obra, destacando nela aspectos que merecem aprofundamento.
\end{abstract}

Palavras-chave: Johann Jakob Von Tschudi. viajantes europeus. Imigração. Século 19.

Abstract: Born in Glarus, Switzerland, Johann Jakob Von Tschudi was for the first time in South America from 1838 to 1843, living in Peru. From 1857 to 1859 he was for the first time in Brazil, returning 1860 as ambassador for the Confoederatio Helvetica. Here he stayed till 1868. As a result of his voyages several books have been printed with precedence for the 5 volumes of his Reisen durch Südamerika (1866-1868). Due the incumbency of the Confoederatio Helvetica to have a look on the situation of Swiss immigrants after the crises generated by the rebellion of the

* Graduado em Teologia e Doutor em História da Igreja pela Universidade LudovicoMaximilianea (1972-1975). Professor do Departamento de História e Pós-Graduação da Universidade do Vale do Rio dos Sinos - UNISINOS. 
Ibicaba Farm, whose memory was preserved by Thomas Davatz, Tschudi gave us not only the memory of this immigration, but also the memory of other European ethnic groups, underlining the clashes with indigenous people and giving us his view of African people. His work is an important source for the point of view of Europeans about the continent. Our presentation of his work intends to show some aspects that need to be studied.

Keywords: Johann Jakob Von Tschudi. European travelers. Immigration. $19^{\text {th }}$ Century.

Ao relacionar os vinte títulos que se deveria ler para conhecer o Brasil, Mário de Andrade mencionou a obra de Thomas Davatz conhecida entre nós sob o título Memórias de um Colono no Brasil, traduzida e prefaciada por Sérgio Buarque de Holanda (Davatz, 1980). A publicação da obra na Suíça contou com o apoio de governos de diversos cantões e pelo próprio governo central da Confederação Helvética e motivou a vinda ao Brasil de Theodor Heusser e de Johann Jakob Von Tschudi, do que resultaram outras duas importantes obras para se entender a imigração e colonização na Província de São Paulo no século XIX, mas não só aí (Heusser, 1857), como veremos quando da apresentação da produção de Von Tschudi. A obra de Davatz que não é objeto da presente exposição é denúncia de opressão, desmandos de poderosos e exposição da reação de oprimidos. É reflexo de modelo de imigração e colonização promovido pelas elites brasileiras que buscavam mão de obra que substituísse a mão de obra escrava (Cohen, 2001). A publicação do texto de Davatz provocou profundas reações na Europa, sendo a mais importante delas a publicação do Rescrito de Von der Heydt, proibindo a emigração de súditos prussianos para o Brasil, mais tarde (1871) estendida ao Reino Alemão. As discussões e as negociações desenvolvidas em território suíço foram trabalhadas por Marlon Ronald Fluck (2004).

No que segue, trabalhamos com o volume 4 da principal obra de Johann Jakob von Tschudi, Reisen durch Südamerika. Leipzig: F.A. Brockhaus, $1868^{1}$. Considerando o espaço possibilitado à presente exposição, também não pretendemos expor o todo do referido volume. O que nos é possível fazer é apresentar algumas das impressões colhidas pelo autor ao visitar o Rio Grande do Sul.

Essa opção deve-se ao fato de este volume não haver sido traduzido para o português. Traduzidos estão os volumes relativos a São Paulo, Rio de Janeiro, Espírito Santo e Minas Gerais. 
Tschudi é natural de Glarus, onde nasceu em 1818. Aos 15 anos dirigiu-se a Zurique, dedicando-se ao estudo das Ciências Naturais. A Universidade de Zurique conferiu-lhe o título de Doutor em Filosofia. Bem ao gosto da época, esteve de 1838 a 1842 viajando pelo Peru. Findas as viagens, apresentou tese de doutorado na Faculdade de Medicina de Würzburg, com a qual obteve também o título de médico. Após a morte de colega, dedicou-se à continuação dos estudos deste sobre minas de diamantes, em Minas Gerais, com o que teve início segunda viagem para a América do Sul, tendo chegado ao Rio de Janeiro em 1857, dedicando-se então a estudos de mineralogia e geologia. No ano seguinte, 1858, visitou os colonos suíços na província de São Paulo. No entremeio também esteve na Bolívia. No início de 1859 retornou à Suíça, encaminhando relatório sobre a situação dos colonos suíços ao Departamento do Interior. Em seguida, foi designado, a 15 de novembro de 1859, Embaixador Extraordinário da Suíça no Brasil, cargo que ocupou de 1860 a 1861. Ao retornar, redigiu obra de cinco volumes Reisen durch Südamerika, publicada entre 1866, em Leipzig, pela editora F. A. Brockhaus. De 1866 a 1882 foi embaixador suíço em Viena.(Fluck, 2004, p. 177)

O quarto volume de suas Reisen durch Südamerika está dividido em quatro capítulos. O primeiro traz suas anotações de visita ao Rio Grande do Sul, em 1861. Neste primeiro capítulo, descreve a entrada da barra, trazendo-nos informações sobre a mesma. Depois traz informações sobre a cidade de Rio Grande e São José do Norte. Ao falar de Pelotas, descreve uma charqueada. Ao rumar para Porto Alegre, fornece informações acerca da Lagoa dos Patos. Muito bem impressionado com Porto Alegre, descreve a cidade, seus principais prédios e a colônia alemã da capital da província. Dedica-se à descrição das condições da colonização com elemento estrangeiro no Rio Grande do Sul, dando destaque a São Leopoldo, a Nova Petrópolis e às demais colônias do distrito. A partir de viagem feita a Rio Pardo, traz informações sobre Santa Cruz do Sul, sobre Santo Ângelo (Agudo), Santa Maria da Boca do Monte e a própria cidade de Rio Pardo. Retornando a Porto Alegre traz panorama sobre a vida intelectual da capital, informa o leitor sobre os projetos relativos à construção de ferrovias e à mineração de carvão. Retornando a Rio Grande traz importantes informações sobre a fauna da região, especialmente na Ilha dos Marinheiros. O segundo capítulo trata de viagem realizada ao longo da costa brasileira, do Rio de Janeiro até São Pedro do Rio Grande, em 1858. Nele, somos informados a respeito da cidade de Santos, o comércio aí realizado, a população e 
o clima. Dedica-se, depois, a informar o leitor sobre a figura de José Bonifácio de Andrada. De Santos segue para São Paulo, passando por São Bernardo do Campo. Somos informados sobre a cultura do chá nesta província, sobre os acontecimentos no Ipiranga, em 1822, sobre a cidade de São Paulo e sobre acontecimentos na Câmara dos Deputados. De São Paulo a viagem segue para Sorocaba, onde o viajante fica impressionado com o mercado de gado, asininos e cavalos. São João do Ipanema, suas instalações e a história da fundição merecem destaque especial. Daí retorna para Santos, apreciando Cananéia, a ilha do Bom Abrigo, Paranaguá, Antonina, São Francisco. Assim como fizera em relação ao cultivo do chá, dedica-se agora à produção da erva mate. Após trazer informações sobre a vida a bordo de embarcações brasileiras, descreve a chegada a Rio Grande. No terceiro capítulo temos relato de viagem de Rio Grande a Rosário, igualmente em 1858. Somos informados sobre tipos humanos que se encontram a bordo, a chegada a Montevidéu, a quarentena na Fortaleza Del Cerro, seguida de descrição da capital uruguaia e do próprio Estado uruguaio. Em Buenos Aires, após descrição da cidade, detém-se em considerações sobre a igreja luterana da cidade, sobre questões relativas à água potável e à perfuração de poços artesianos, a população, escritores, educação, escola, o Museu de História Natural, os clubes e o associativismo, o governo, imigrantes. Assim como se dedicou a José Bonifácio, dá atenção a Juan Manuel Rosas. Pelo Paraná, a viagem segue até Rosário. O quarto capítulo, finalmente, está dedicado à viagem de Rosário a Catamarca. Descreve a cidade portuária de Rosário, um encontro com bascos, as colônias. Segue com a descrição de viagem de Rosário até Córdova, passando por Candelária, onde se depara com indígenas do Pampa, segue para Parada de Lobaton, Fraile Muerto, Esquina de Mederano, Rio Tercero, Cañada, Los Espinillos, Rio Segundo, Punta Del Monte. Em Córdova vê e descreve igrejas, a universidade, diz do assassinato do General Quiroga. Assim, com minúcias vai descrevendo encontros e localidades até chegar a Catamarca.

A descrição de conteúdos feita acima, nem de longe consegue reproduzir toda a riqueza desse volume que continua à espera de tradução. No que segue, procuramos trazer, parcialmente e de forma mais detalhada, aspectos do capítulo primeiro.

Em sua segunda visita ao Rio Grande do Sul, Tschudi aqui chegou a 11 de março de 1861. Entrementes, são decorridos 150 anos. É óbvio que sua chegada se dá via Rio Grande. Descreve-nos a barra, as dunas, impressiona-se com o "Pampeiro" e sua impetuosidade, com os 
"vagalhões" e com a "barra brava". Sabe dos perigos do assoreamento e recomenda o plantio de vegetação apropriada nas dunas. Viajantes sempre sabem fazer recomendações.

De Rio Grande faz excursão a Pelotas para visitar uma "Xarqueada" à bordo do "Continentista". A charqueada visitada pertence a um alemão, "Senhor Elster". Os maus odores afetam suas narinas e os milhões de moscas com asas pegajosas, tão pacíficas que parecem querer transformar o ser humano ainda vivo em depósito de seu ninho, não lhe deixam paz. Considera difícil alimentar-se aí, pois os bocados têm que ser disputados com as moscas. Descreve também a produção associada à charqueada: sebo, velas, pelos e óleos, preparo de couros. A primeira charqueada, assim Tschudi, data de 1794. Em 1820 havia dez delas. Em 1960 , seus produtos representavam o principal produto de exportação da Província. Constato: Tschudi se interessa por geografia, por alemães, por economia.

São Francico de Paula de Pelotas tem, à época de sua visita, entre 8 e 9 mil habitantes. Tschudi situa a origem da cidade numa "xarqueada". A construção de uma igreja teria dado início à cidade. Louva as casas construídas, a riqueza da elite, instituições de caridade e escolas.

Em 21 de março, a viagem continua, agora com o "Proteção", rumo a Porto Alegre, superlotado. Companhia lírica estava a bordo. A viagem dura 24 horas. Descreve Porto Alegre, vista do Guaíba. Deparase com o Colégio Santa Teresa, a igreja do Menino Deus, o cemitério, o novo presídio. Na cidade, aloja-se na residência de Friedrich Bier, comerciante e outrora colono em São Leopoldo. Porto Alegre é "a mais amável e agradável de todas as capitais provinciais que conheço" (p.9). Suas ruas, em linha reta têm calçamento ruim. As casas de dois andares são sólidas e confortáveis e de bom gosto. Algumas têm a fachada com azulejos de fayence. Impressionam-no os prédios públicos (cadeia, arsenal, arsenal da marinha, teatro, hospital, alfândega. Um mercado está sendo construído). Fica maravilhado com a Praça Dois de Dezembro (antes Largo da Forca), mas decepciona-se com os poucos cuidados que se tem com ela. Depois de inauguradas, obras são relegadas. A cidade conta com 20.000 habitantes, dos quais $1 / 3$ são estrangeiros. Os alemães são 500 indivíduos. Em 1857 houve aí epidemia de cólera: mais de 4.000 pessoas foram vitimadas.

A cidade não tem caráter germânico como muitos afirmam. Lembro que Tschudi tem concorrente no mercado livreiro: o médico hamburguês Robert Avé-Lallement que descreveu Porto Alegre germânica. Mesmo assim, o suíço concorda que há forte presença germânica na cidade, o 
que pode ser constatado nas inscrições em casas comerciais, oficinas, bares, hotéis. Os alemães são originários de São Leopoldo, acrescidos de ex-integrantes da Legião Alemã. Artesãos são alemães, alemães são os proprietários das maiores casas comerciais. Há muitas sociedades (clubes) alemães: Sociedade Auxiliar, de Canto, de Leitura. Destaque merece o jornal "Deutsche Zeitung". Redator deste jornal era, à época da visita de Tschudi, um certo Senhor C. v. Koseritz.

A cidade não é feita apenas de "bons" alemães. Tschudi denuncia um alemão J. H. Knorr por haver trazido a Porto Alegre grande quantidade de criados alemães. Em três navios, mais de cem indivíduos, homens e mulheres, teriam sido importados por Knorr. As mulheres haviam sido recrutadas em bordéis alemães e a maioria pereceu miseravelmente em Porto Alegre.

Em relação aos alemães, o suíço constata forte nativismo antiestrangeiro, liderado por Felippe Betbazé d'Oliveira Nery, Diretor da Repartição das Terras Públicas, antes Tesoureiro da Província. A discussão girava em torno da questão, se estrangeiros poderiam ser diretores de colônias. Aqui é importante lembrar que João Daniel Hillebrand fora nomeado diretor da Colônia Alemã de São Leopoldo e que o Barão von Kahlen fora designado diretor da Colônia de Santo Ângelo, hoje Agudo, e depois de São Lourenço do Sul.

Partindo de Porto Alegre, Tschudi visita São Leopoldo, colônia iniciada em 1824. A viagem de ida é feita por terra. O retorno acontece com "vapor". A ida é feita pelo "Caminho Novo", passa pela estância do General Netto², segue até o Arroio de José Joaquim. Tschudi chega a São Leopoldo no Domingo de Ramos. No caminho, depara-se com meninas vestidas de branco e grinaldas no cabelo. A descrição é indicativo de que, segundo tradição luterana, acontecera a confirmação e de que no domingo seguinte, o domingo da Páscoa, as pré-adolescentes participariam pela primeira vez da eucaristia. Em São Leopoldo, hospeda-se no Hotel Koch.

São Leopoldo tem ruas arenosas, casas baixas, lembrando aldeias húngaras. Há muitas construções em andamento. Estava sendo construído prédio maior que serviria de teatro, casa de baile e cassino. Havia sido lançada pedra fundamental para casa de governo e parte das paredes havia sido levantada, mas o dinheiro acabara. Tschudi refere-se a atual Sociedade Orpheu e ao prédio da Intendência. Em São Leopoldo, a primeira pessoa a ser visitada é o médico e Capitão da Guarda Nacional

\footnotetext{
Aqui há evidente erro de informação.
} 
João Daniel Hillebrand. Tschudi menciona o Relatório produzido por Hillebrand e que só viria a ser publicado em 1924. Nota-se que suas informações baseiam-se em Hillebrand. À noite visita o pastor luterano Wilhelm Klenze que faleceria no domingo seguinte, durante o sermão, vitimado por infarto.

Tschudi oferece relato abrangente sobre a instalação da Colônia e sobre os colonos aí chegados e assume o discurso de que todos os males da Colônia advêm de ex-presidiários de Mecklenburg-Schwerin (Dreher, 2010). Critica as medições de terra. Fala de confrontos com indígenas e coloca a data de 1852 como último ano de confronto entre indígenas e colonos ${ }^{3}$. Tschudi também nos informa que José Thomás de Lima, primeiro diretor da Colônia, era filho bastardo de Monsenhor Pedro Machado de Miranda Malheiros, Imperial Inspetor da Colonização Estrangeira. Segundo Tschudi, Tomás de Lima seria responsável por diversas irregularidades, entre elas violência sexual em relação a mulheres imigrantes. Como proprietário de "Vendas" explorava os colonos economicamente. Após a destituição de Lima, a colônia teria prosperado. Essa prosperidade, contudo, teria sido interrompida pela Revolução Farroupilha. Na Revolução, os colonos católicos e os dois pastores protestantes teriam se colocado ao lado dos farrapos, enquanto os colonos protestantes teriam permanecido ao lado dos imperiais. Toda a sorte de atrocidades foram cometidas na Colônia, tendo havido decréscimo no número de habitantes, também em virtude de transferência para outros rincões da Província.

Tschudi também visita as picadas de São Leopoldo. Dá destaque a Bom Jardim (Ivoti), onde além da produção agrícola constata boa produção de vinhos. Na Venda de Blauth, no "Buraco do Diabo", descreve compra de produção de feijão, que à época está perfazendo a riqueza dos agricultores. De Bom Jardim, a viagem segue em direção a Dois Irmãos, depois de ter sido apreciada a queda d'água da Picada 48. Ao retornar, passa por Novo Hamburgo. Tschudi deixa São Leopoldo muito bem impressionado. Considera a Colônia revide a insinuações existentes na Europa de que colonização com europeus seria impossível e impraticável no Brasil. Considera que o idioma alemão se manterá com seus dialetos por diversas gerações na região. Admira os imigrantes e seus descendentes por haverem abandonado

3 Em todos os volumes de sua obra, Tschudi faz referência a conflitos com indígenas. As informações mais cruéis acerca do holocausto indígena foram feitas em relação à atual Teófilo Ottoni, em Minas Gerais. 
o "servilismo" que os caracterizara e considera totalmente factível a convivência do elemento germânico com o elemento românico, com o qual o imigrante se comunica fazendo uso da língua portuguesa. Destaca também a crescente participação política dos imigrantes e sua participação na mesma em Santa Maria da Boca do Monte, para onde se dirigiram descendentes de imigrantes de São Leopoldo. Lamenta, porém, que em alguns distritos, os colonos estejam sujeitos a maus tratos de parte de autoridades subalternas. Aponta também para conflitos em torno da terra, resultantes de más medições feitas quando do início do povoamento. Refere as discussões havidas a esse respeito de parte do Embaixador Prussiano von Eichmann e dele próprio junto ao Ministério de Relações Exteriores.

Tschudi não deixa de relatar os conflitos religiosos surgidos na Colônia Alemã de São Leopoldo desde a chegada de sacerdotes jesuítas. Afirma que até a chegada destes, as relações entre católicos e protestantes eram muito boas. A partir de então, em São Leopoldo, no período em que o Pe. Bonifácio Klüber sj aí atuou os conflitos disseram especialmente respeito a matrimônios mistos. Klüber teria investido contra esses matrimônios e, em 1864, teria casado mulher protestante já casada com um protestante com um cônjuge católico. Para Tschudi o fato configurava bigamia, para o Pe. Klüber o matrimônio anterior da protestante inexistira, pois não fora realizado na presença de sacerdote católico. Segundo Tschudi, o presidente da província teria exigido a saída de Klüber de São Leopoldo.

Sempre interessado na produção da colônia, Tschudi dedica atenção ao couro e à produção de selas que são exportadas a partir de São Leopoldo. Destaca a produção de cola como subproduto do couro. Dentre os produtos agrícolas exportados os principais são feijão, milho e batatas. Verifica, também, que há forte tendência de parcelamento das propriedades, o que tem levado muitos descendentes a migrar para novas fronteiras agrícolas.

Depois de visitar São Leopoldo, Tschudi dirige-se a Nova Petrópolis, Mundo Novo, Conventos, Estrela e vê como auspiciosa a instalação da colônia de Teutônia. Em diversas dessas colônias refere choques com indígenas.

Em 3 de março, segue com o "Rio Pardense" para visitar Santa Cruz. Saindo de Porto Alegre, passa por Triunfo, pela Vila de Santo Amaro. Próximo a Santo Amaro vê o maior jacaré com o qual já se vira confrontado na América do Sul. Em Rio Pardo é recebido por alemão que o conduz até Santa Cruz. Passa pelo "Aldeamento de São Nicolau". 
Sugere que os indígenas sejam colocados sob diretor e que parte das terras lhes sejam tiradas e promovida colonização. Na época de sua visita, as terras do Rincão Del Rey estão sendo parceladas. Em Santa Cruz já há próspera colônia. Dois centros estão sendo preparados para a colônia: São João e Santa Teresa. A colônia já se destaca pela produção de tabaco. Os colonos se ressentem da falta de pastores e professores, além de escolas.

Tschudi não consegue visitar a colônia de Agudo, pois há "inquietação" em Cachoeira do Sul. Visita, no entanto, Santa Maria, onde os alemães elegeram quase todos os vereadores em 1860. Apenas dois seriam "brasileiros". Ao retornar, descreve Rio Pardo, suas ruas, seus prédios. Chegado a Porto Alegre, visita o arquivo do Presidente da Província e estuda os mapas produzidos por Woldemar Schulz. Constata que a população de Porto Alegre não demonstra grande interesse por estudos superiores: O Liceu Dom Affonso tem pouquíssimos alunos. O Seminário tem mais alunos que o próprio Liceu. Maior é seu interesse em relação aos ramais ferroviários que estão sendo projetados. Detémse nas descobertas de carvão em Candiota e Arroio dos Ratos e prevê a possibilidade de exportação de carvão para o Prata, para o abastecimento de navios que atracam em portos brasileiros. As ferrovias e a continuação da imigração alemã fazem-no prever futuro brilhante para o Rio Grande do Sul.

Feitos os relatos sobre os diversos projetos de colonização que encontrou no Rio Grande do Sul, vale-se de dois relatórios de diferentes ministros da agricultura do Império para considerações. Um dos ministros considera que o projeto de colonização fracassou, pois não está conseguindo oferecer os braços de que carece a agricultura em substituição a braço escravo que diminui. Melhor seria enviar filhos da elite aos Estados Unidos, onde poderiam aprender novas técnicas. Tschudi rebate: de que adiantam novas técnicas se falta elemento humano num país de baixa densidade populacional. O sucessor desse ministro, por sua vez, apóia a entrada de mais imigrantes. Daí que Tschudi crítica a política imigratória: não há consenso no Brasil. O que há é desvio de recursos e falta de planejamento. Para ele, no entanto, o Rio Grande do Sul é exceção. Aqui, quando da instalação das colônias, houve logo preocupação com o mercado para os excedentes produzidos. Em outras províncias, os colonos foram lançados na mata e não houve preocupação quanto a mercados nem quanto a escoamento. Lembra que o imigrante não vem apenas para ter o que comer, mas também para poder transformar o excedente de sua produção em dinheiro. Volta-se, 
também, contra tendências então existentes no Brasil que preferem colonização com elemento nacional. Novamente Tschudi argumenta com a baixa densidade populacional. O Brasil tem que fomentar a imigração, o que lhe falta é legislação que assegure igualdade de direitos aos imigrantes. Dá destaque a um aspecto, onde é urgente que ocorra mudança: o reconhecimento dos matrimônios dos acatólicos.

Interessante é sua crítica às colônias particulares. Segundo ele, as colônias particulares sempre acabam por ser administradas pelo governo, pois seus idealizadores vão à falência. Lembra a colônia do Conde de Montravel, no Rio Grande do Sul, e a colônia de Hermann Blumenau, em Santa Catarina. Importa promover as colônias já instaladas e criar novos núcleos em sua proximidade. Critica as recentes instalações de particulares como a colônia de belgas no Paraná, instalada por Madame van Langendonck, e o empreendimento do General Wood que pretende trazer norte-americanos para o Brasil. Mesmo assim, louva a criação, na Europa, da Sociedade Internacional de Colonização, em 1866, cujos estatutos reproduz em seu texto. Por fim, julga ser injustificada a campanha contra a emigração ao Brasil. O exemplo do Rio Grande do Sul demonstra as boas possibilidades, pois aí há alemães e descendentes contentes.

Ao retornar à cidade de Rio Grande, descreve-a em detalhes, bem como sua história e desenvolvimento. Em uma população de cerca de 19.000 habitantes há 5.000 escravos. Há nela hospedaria e um hospital, a Santa Casa de Misericórdia. O comércio é florescente, há importação e exportação, mas as tarifas alfandegárias do Brasil dificultam a concorrência com o Uruguai. Na Ilha dos Marinheiros participa de caçada e fornece impressionante relato sobre a fauna que ali encontra.

A 20 de abril toma o vapor "Apa", vindo de Montevidéu, em direção ao Rio de Janeiro. No navio viajam os deputados do Rio Grande do Sul, mas liberais e conservadores não conversam entre si. A caminho do Desterro, o "Apa" cruza com esquadra comandada pelo Almirante Tamandaré. No Desterro embarca o presidente Brusque, recentemente destituído de suas funções.

Tschudi também é representante dos "olhos do império" (Pratt, 1999), mas o fato de ser suíço, assim me parece, permite que tenha olhar diferenciado e mais sóbrio do que outros autores do período. Isso lhe permite, por exemplo, criticar as posturas da Prússia em relação à emigração e apresentar defesa de sua continuidade. Trata-se de autor que merece ser mais estudado entre nós. 


\section{Referências}

AVÉ-LALLEMANT, Robert. Viagem à Província do Rio Grande do Sul (1858). Belo Horizonte: Itatiaia, 1980.

COHEN, Ilka Stern. Thomas Davatz revisitado: reflexões sobre a imigração germânica no século XIX. In: Revista de História, São Paulo, n. 144, jul. 2001.

DAVATZ, Thomas. Memórias de um colono no Brasil (1850). Belo Horizonte: Itatiaia; São Paulo: EDUSP, 1980.

DREHER, Martin N. Degredados de Mecklenburg-Schwerin e os primórdios da imigração alemã no Brasil. São Leopoldo: OIKOS, 2010.

FLUCK, Marlon Ronald. Basler Missionare in Brasilien. Auswanderung, Erweckung und Kirchenwerdung im 19. Jahrhundert. Bern: Peter Lang, 2004.

HEUSSER, Theodor. Die Schweizer auf den Kolonien in St. Paulo in Brasilien. Bericht des Herrn Heusser an die Direktion der Polizei des Kantones Zürich. Zürich: Druck und Verlag von Friedrich Schulthess, 1857.

PRATT, Mary Louise. Os olhos do império: relatos de viagem e transculturação. Bauru: EDUSC, 1999.

TSCHUDI, Johann Jakob Von. Reisen durch Südamerika. Vierter Band. Leipzig: F.A. Brockhaus, 1968. 